\title{
Punching Shear Resistance of Reinforced Concrete Flat Slabs Strengthened by CFRP and GFRP: A Review of Literature
}

\author{
Hadi N. G. Al-Maliki ${ }^{a}$, Ali Al-Balhawi (D) ${ }^{\text {b }}$, Asma M. Ali \\ Civil Engineering Department, Engineering College, Mustansiriyah University, Baghdad, Iraq. \\ *Corresponding author Email: dr.hadialmaliki@uomustansiriyah.edu.iq
}

\section{H I G H L I G H T S}

- Flat reinforced concrete slabs are widely used in buildings.

- Flat slab systems have inadequate shear strength in both directions.

- Strengthening by using CFRP and GFRP enhances the punching shear resistance.

- Recent studies of enhancing the shear resistance of flat slabs were reviewed.

\section{A R T I C L E I N F O}

Handling editor: Wasan I. Khalil

Keywords:
CFRP
GFRP
Flat
Improvement
Punching shear
Strength
Capacity

\begin{abstract}
A B S T R A C T
Flat reinforced concrete (RC) slabs or plates are still widely used in buildings and are most popular in single or multiple story floor construction systems. This is due to the ease and speed of implementation as well as the continuous smoothness that is provided in relation to the locations of members. Flat slab systems have an inadequate shear strength in both directions. Thus, they are subjected to a shear failure at their intersections with columns, which results in the collapse of a larger part of the structure. Shear failure occurs due to many reasons including changing the functions of the facility, the technical errors in the design and implementation procedures, an increase in the load, deterioration of materials, and poor quality. The carbon fiber reinforced polymer (CFRP) sheets/strips and glass fiber reinforced concrete polymer (GFRP) are used as a composite section formulated when there is a structural deficiency. Strengthening by using CFRP and GFRP provide an improvement in the punching shear resistance in both directions as well as flexural strength, ductility, and hardness. They are more suitable for a practical use as a substitute for other costly and difficult approaches such as increase the cross-sectional area of columns and so on. This paper reviews the up to date studies of enhancing the shear resistance of flat slabs by CFRP/GFRP and discusses the used materials for strengthening flat slabs and the used methods, which are used to implement these materials. Also, a summary for the cited studies are stated and the possible future works are suggested.
\end{abstract}

\section{Introduction}

In general, the process of strengthening for buildings has been rapidly growing in recent decades in the field of civil engineering. Therefore, it was necessary to create and develop the appropriate techniques to improve and increase the resistance of structural members in inexpensive and effective ways. Experiments have proved that installing CFRP panels on the surface of reinforced concrete slabs is considered an economical and effective technique as well as they can be used in other structural members, i.e. beams and columns. Thus, many studies have shown that using CFRP for strengthening members is the most appropriate material for improving the strength capacity of slabs such as punching shear resistance [1]. The shear mechanism is not fully understood, but there are many methods, which have been used in the previous decades to avoid and prevent this type of failure. The punching shear failure is classified into four stages. The first one is the crack propagation because of bending and shear failures at the tension region of the slab in closing to the face of the loaded locations. The second one is that the steel reinforcement undergoes a slab tightening in closing to the side of the loaded locations. Whereas, the third stage represents the flexure and shear cracks, which can extend to the compression zone of a member. Finally, the failure extends beyond the loading zone and occurs before the yielding of steel. In addition, one of the causes of the expected shear failure is the resulting fracture in the compression zone of the slabs [2]. The surface shape of the shear failure is conical and surrounded by critical inclined cracks that meet the horizontal cracks in parallel to the reinforcing steel up to the reinforcing rebar in the tension area [3]. The behavior of a slab under applied loading includes a linear elastic response due to the applied loading on a slab-column's connection area. Then, the stiffness of the slab is reduced at connections due to initial cracks. Also, 
the deflection pattern of the slab in the compression zone can be considered as a straight line. While, it is noted that cracks are not continuous and few, especially in the area where the shear crack congestion with steel reinforcing in the tension area [4].

Silva et al. [5] investigated the behavior of strengthening flat slabs with CFRP plates in terms of punching shear capacity. The strengthening technique was divided into two groups including orthogonally and skewed attached CFRP strips. They stated that using lightweight CFRP and adhering them with their glue or fixing with anchors bolts to the concrete surface can increase the resistance of flat slabs against punching shear, especially when the fastening is skewed from the column axis directions. In general, they indicated that the specimens strengthened with CFRP attached at the tension face with steel end anchors have an enhancement of $46 \%$ as maximum average increase in the punching shear capacity. In correspondence to this increase, a reduction of $11 \%$ was indicated in the midspan deflection in the strengthen specimens. Similarly, the ultimate flexural resistance of flat slabs is increased with installing the CFRP sheets, strips or laminated to the tension area of the concrete [6].

Al-Quraishi [7] studied the effect of using fibers content in Ultra-High-Performance Concrete (UHPC) slabs on the punching shear resistance. He stated that the mechanical performance of a UHPC member is strongly dependent on the content and orientation of steel fiber. Also, he indicated that the failure plane includes fiber amount, which differs in comparison with those amounts used in the prepared model before testing. Sayhood et al. [8] investigated numerically the punching shear resistance of RC flat slabs strengthened with CFRP strips. Also, the nonlinearity of materials has been included in the numerical models to simulate the effects of concrete cracking, crushing of concrete, and yielding of reinforcement. They stated that the ultimate load capacity was increased to $8.83 \%$ for the strengthened models with CFRP in comparison with those unstrengthen models. Medhlom [9] experimentally investigated the behavior fibrous self-compacting concrete (FSCC) slabs in terms of punching shear resistance. The studied parameters include volumetric steel fiber ratio, removing limestone powder from mixing, slab thickness and steel reinforcement ratio. He stated that the effect of slab thickness and steel fibers are more significant in increasing the ultimate load capacity, stiffness, ductility, reduced crack width of the strengthened slabs. Also, the increase in the volume fraction of steel fiber results in decreasing the perimeter of punching shear section.

\section{Evaluating Punching Shear Resistance Capacity in International Design Codes and Standards}

Punching shear resistance capacity can be evaluated in both directions by the proposed specifications in the international building design codes and standards. However, these codes and standards contain different formulas and specifications in terms of the considered parameters in each country for evaluating the shear resistance of flat slabs. These formulas according to the American code ACI-318 [10], the British Standard BS-8110 [11], Eurocode 2 [12] and the Canadian Standards CSAS806 [13] are briefly illustrated in Table 1. Theoretically, ACI [10] and CSA-S806 [13] provide a conservative design for punching shear due to the closest distance of critical section to the support and other parameters. However, the rest of standards/codes provides overestimate values for punching shear design resistance.

Table 1: Punching shear design formulas according to the international design codes and standards

\begin{tabular}{|c|c|c|}
\hline Code/Standard & C.S.L* & Formula \\
\hline BS-8110 [11] & $1.5 \mathrm{~d}$ & $\begin{array}{c}\text { The least of: } \\
0.33 \lambda \sqrt{f_{c}} \text { bo d } \\
\left(0.17+\frac{0.34}{\beta_{0}}\right) \lambda \sqrt{f_{c}} \text { bo d } \\
0.083\left(2+\frac{\alpha_{s} d}{b_{0}}\right) \lambda \sqrt{f_{c}} \text { bo } d \\
V_{c u}=0.79\left(100 \rho_{f} \frac{E_{f}}{E_{s}}\right)^{1 / 3}\left(\frac{400}{d}\right)^{1 / 4}\left(\frac{f_{c k}}{25}\right)^{1 / 3} b_{1.5} d\end{array}$ \\
\hline Eurocode 2 [12] & $2 d$ & 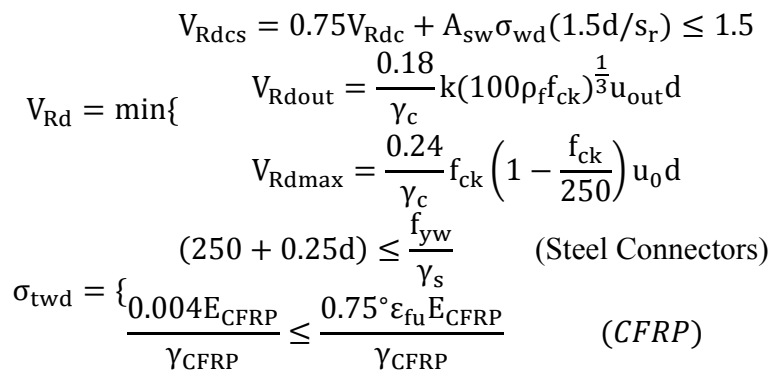 \\
\hline CSA-S806 [13] & $0.5 \mathrm{~d}$ & $\begin{array}{c}0.028\left(1+\frac{2}{\beta_{c}}\right) \lambda \emptyset_{c}\left(E_{f} \rho_{f} f_{c}^{\prime}\right)^{\frac{1}{3}} b_{0.5} d \\
V_{c}=\min \left\{0.147\left(0.19+\alpha_{s} \frac{d}{b_{0.5}}\right) \lambda \emptyset_{c}\left(E_{f} \rho_{f} f_{c}^{\prime}\right)^{\frac{1}{3}} b_{0.5} d\right. \\
0.056 \lambda \emptyset_{c}\left(E_{f} \rho_{f} f_{c}^{\prime}\right)^{\frac{1}{3}} b_{0.5} d\end{array}$ \\
\hline
\end{tabular}


*C.S. L: Critical section location.; the rest of factors is defined in the cited codes and standards.

\section{Strengthening with CFRP Patterns and the Installation Methods}

This section includes details of experimental results and presentation of strengthening methods for RC flat slabs. Harajli and Soudki [14] tested squared RC flat slab with a reinforcing ratio of $1 \%$ and $2 \%$. CFRP strips with variable widths of (50, $100,150,200) \mathrm{mm}$, were used as shown in Fig. 1. They indicated that using CFRP strips as strengthening for flat slabs in the tension area can provide an increase in the punching shear resistance about (17\% to $45 \%)$ in comparison to the nonstrengthened slabs. This strengthening mechanism increases the shear force in both directions by making cracks in the tensile area and when the bending resistance increases at the junctions. Therefore, the tension side of flat slab when strengthened at column region may convert the type of failure from flexure to the shear-flexure or to the punching two-way shear. Sharaf et al. [15] investigated the influence of using CFRP strips on the punching shear failure. The studied parameters were using different amounts and configurations of CFRP. They show that flat slab strengthened with externally CFRP strips around the columns at tension side provides an increase in the stiffness of the slab by about $(29-60 \%)$ when compared to the non-strengthened specimens. Also, the punching shear strength was increased by about (6\% to $16 \%)$ due to the increase in the corresponding stiffness around the column at the strengthened tension side. The CFRP strips delay the beginning of flexure cracks and control their distribution. They stated that the shear failure is predominant in the tested specimens. They also studied the effect of arranging the strips at the tension side of flat slabs as shown in Fig. 2.

Radik et al. [16] studied the effect of using strips of glass fiber reinforced polymer (GFRP)in squared RC flat slabs on the maximum load capacity and ductility. The slabs were fixed at two perpendicular directions in the tension zone as shown in Fig. 3. Also, the arrangement of GFRP strips and the layout of the testing device are shown in Fig.3. They stated that the maximum load capacity and ductility were increased due to the use of GFRP strips in comparison to other non-strengthened specimens. The load-deflection curve of the strengthened specimens is shown in Fig. 4.

Esfahani [17] experimentally studied the effect of using the CFRP for squared flat slabs with two percentages of reinforcing ratio $(0.84,1.59)$ on the resistance of punching shear as shown in Fig. 5 . Also, the used loading was monolithic and cyclic. He stated that in terms of the former load, the used CFRP provides an increase in the punching shear strength. Whereas in terms of the cyclic loading, the used CFRP does not significantly affect the punching shear resistance. In addition, the increase of steel reinforcement ratio can increase the effect of using CFRP.

Abbas et al. [18] studied the effect of using unidirectional CFRP sheets for squared flat slabs supported only on parallel two sides on the strength capacity. A layout of the tested slab strengthened with CFRP sheets is shown in Fig. 6. A steel pipe of $40 \mathrm{~mm}$ diameter was used for applied loading to the models. They show that the strengthened flat slabs can provide an enhancement in the strength capacity of $12.4 \%$ and $16.4 \%$ for the corresponding concrete strength of (39.9 and $63.2 \mathrm{MPa})$, respectively. Also, they noticed that the presence of two peaks in the load-deflection curve as shown in Fig.7, which the first peak is related to the punching shear failure in the concrete followed by the reduction in the curve due to the resistance that is generated from the movement of in the aggregate interlock and the effect of dowel action for the steel reinforcement.

El-Salakawy et al. [19] experimentally investigated samples of specified RC flat slabs supported on squared edge columns with steel reinforcing ratio of $0.75 \%$ and $0.45 \%$ in the tension and compression zones in both directions, respectively. The width of the strips used for stiffening the samples with using carbon fiber was $50 \mathrm{~mm}$. While the glass fiber width was $75 \mathrm{~mm}$. They used L-shaped strips with vertical orientation on unrestricted edges and straight strips were also fixed to tension reinforcing location of concrete section that were parallel to the main reinforcement in all directions as shown in Fig. 8. They stated that the fixed CFRP/GFRParound the column at the tensile region of the flat slab enhances the flexural resistance and delay the appearance of cracks. Also, bending and punching shear strengths were improved.

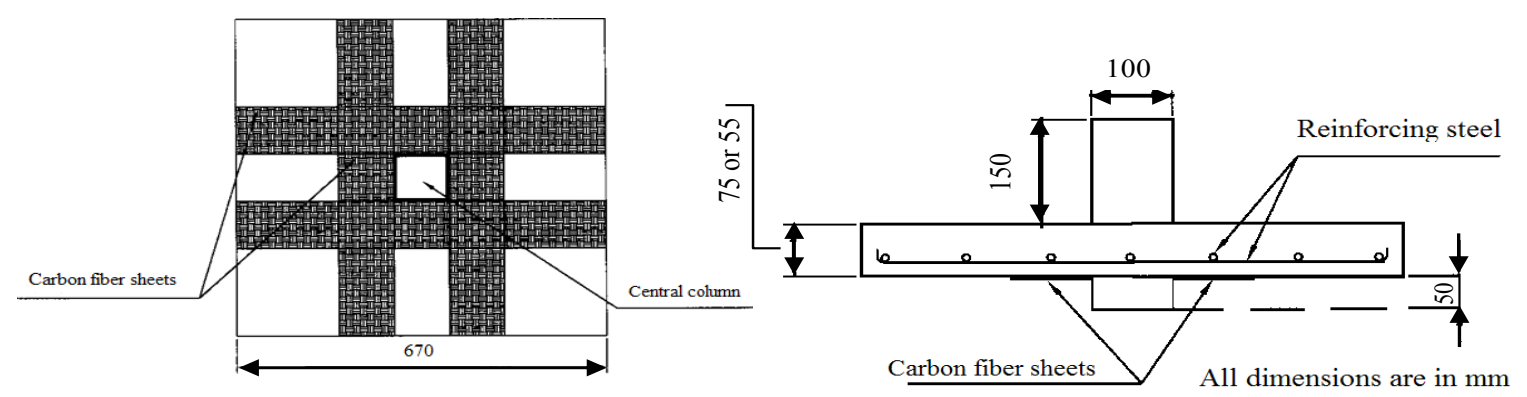

(a)

(b)

Figure 1: Tested RC specimens and CFRP strips, (a) CFRP strip layout fixed at tension side, and (b) RC slab section details [14] 

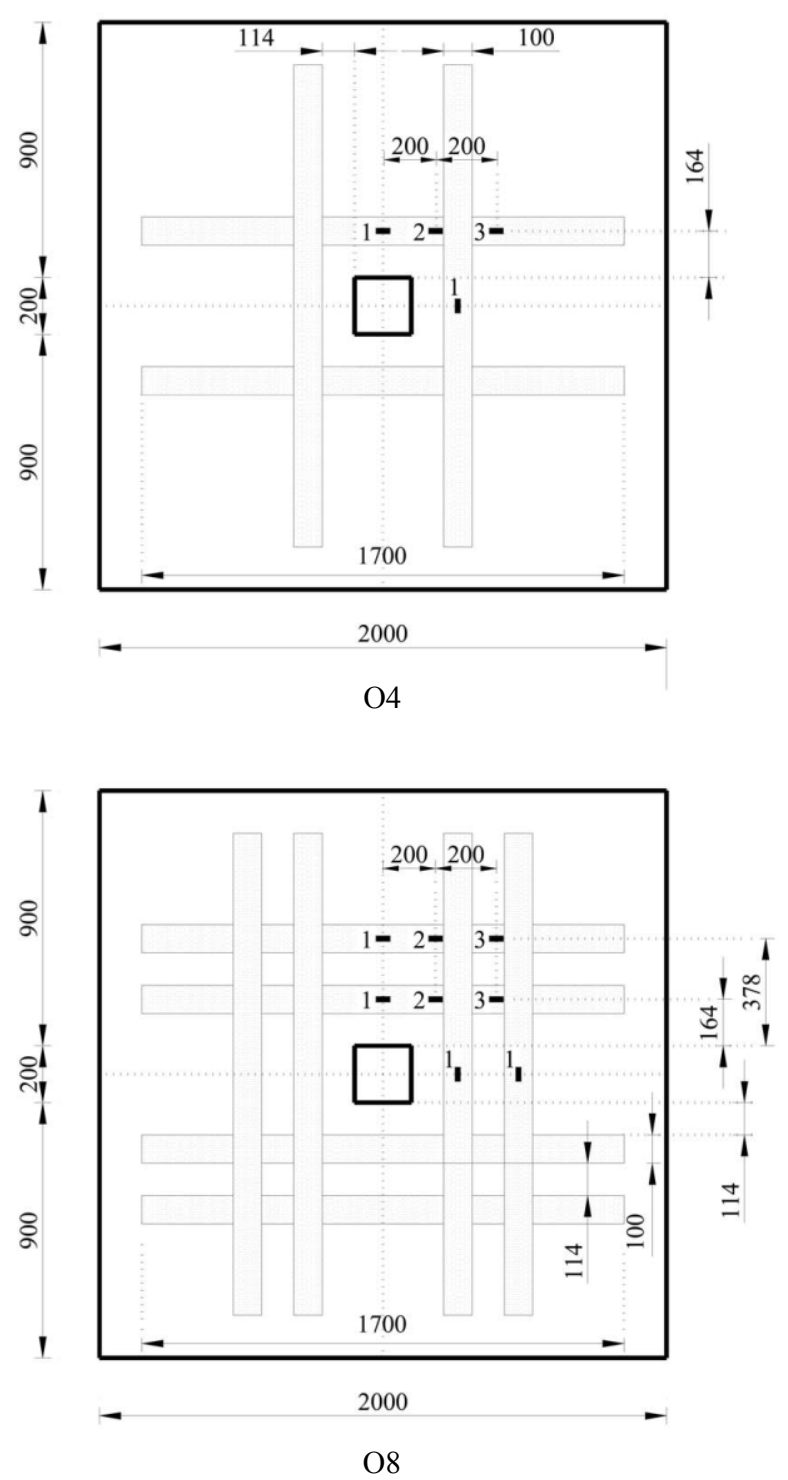
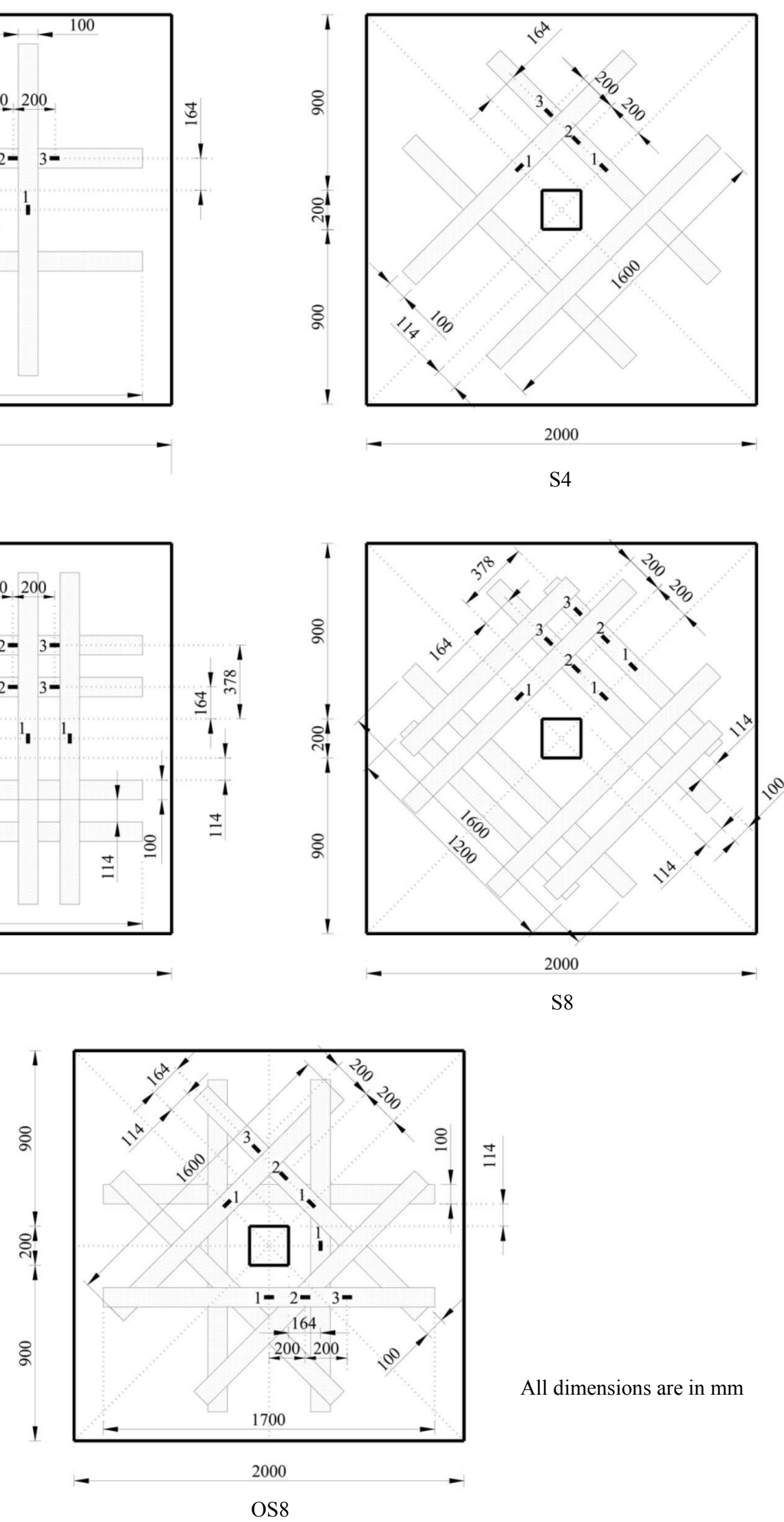

All dimensions are in $\mathrm{mm}$

Figure 2: CFRP strips layout: orthogonal to column (O4 \& O8), skewed to column (S4 \& S8), and mixed orthogonal and skewed (OS8) [15] 


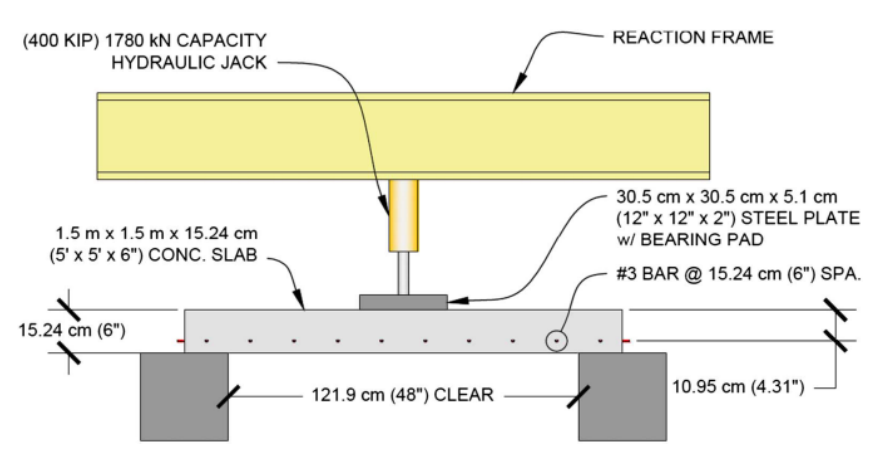

(a)

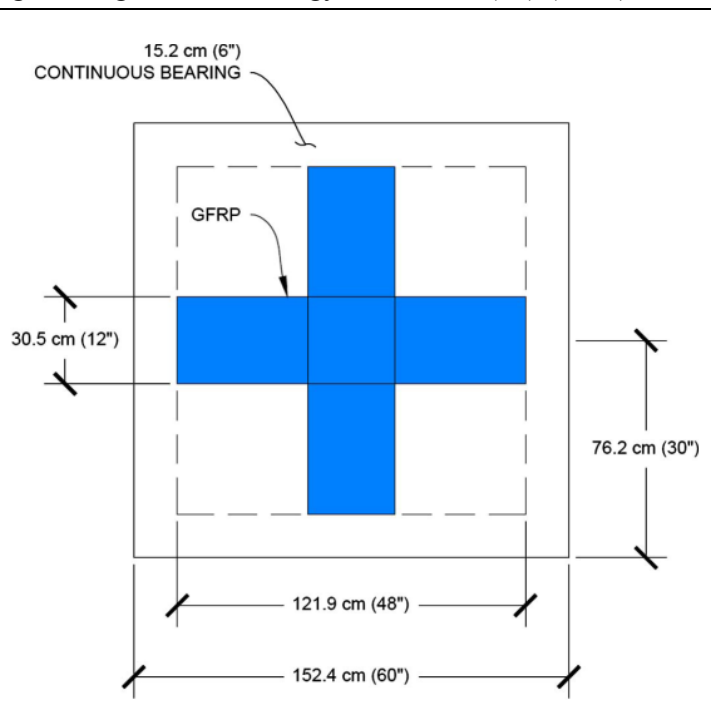

(b)

Figure 3: (a) Test setup layout, and (b) GFRP strips location at the tension face [16]

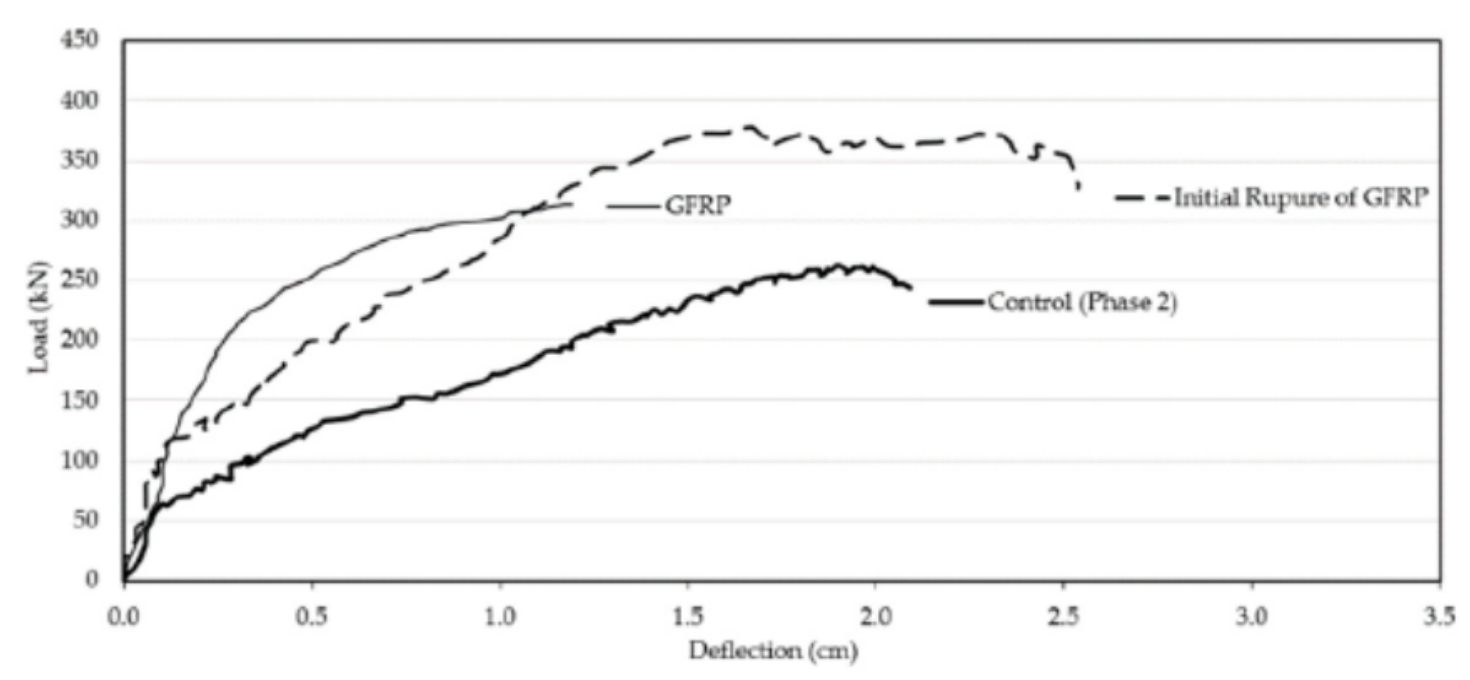

Figure 4: Load-deflection curve for the strengthened specimens [16]

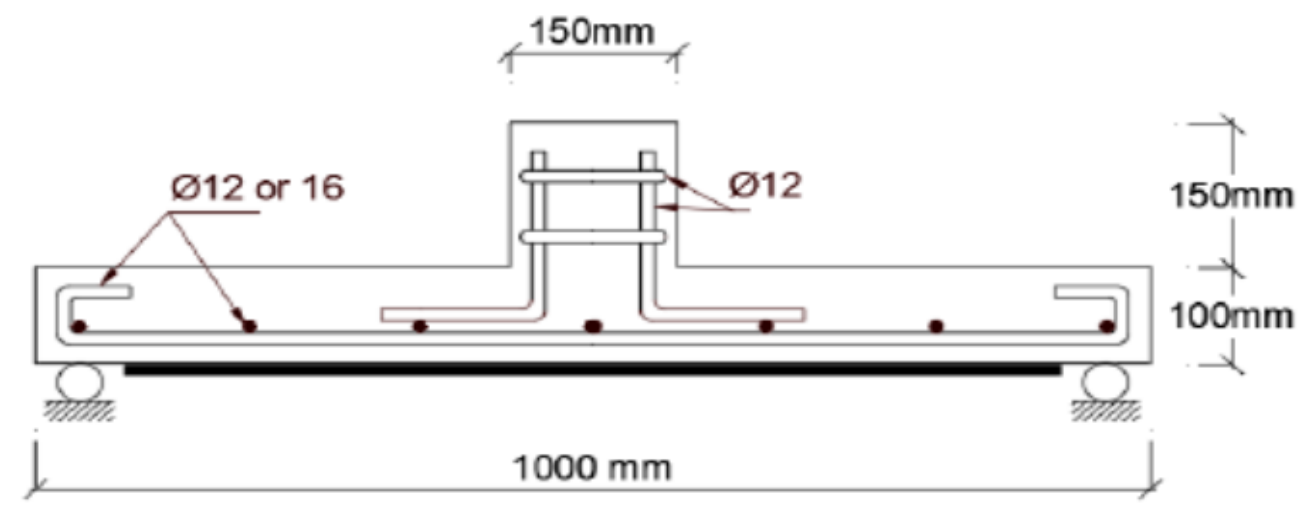

Figure 5: CFRP sheets and location at tension zone of specimen [17] 


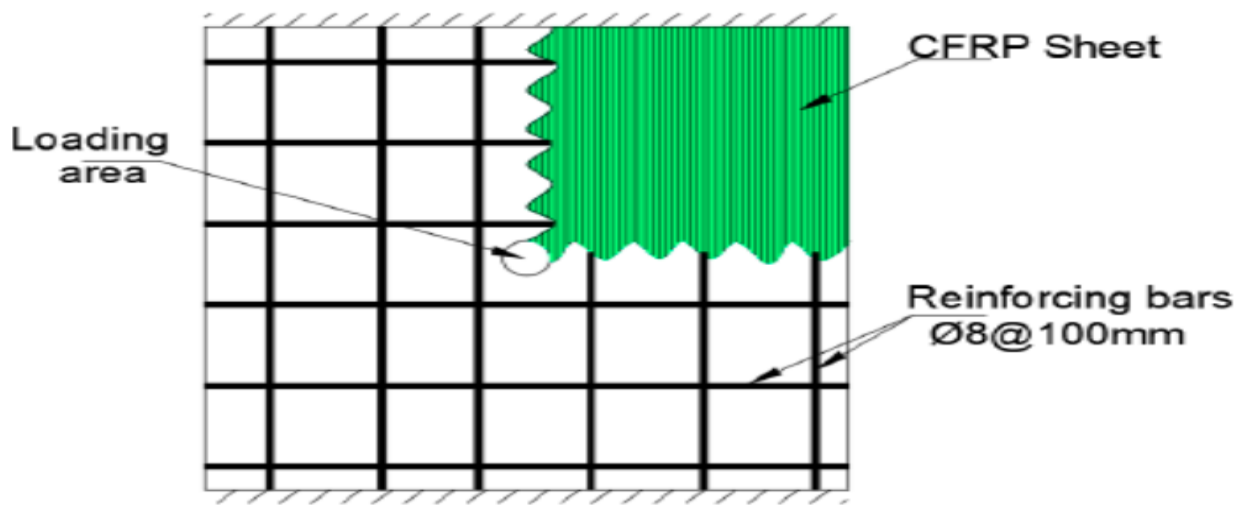

Figure 6: Enhancement of a unidirectional supportive concrete sample with CFRP sheet [18]

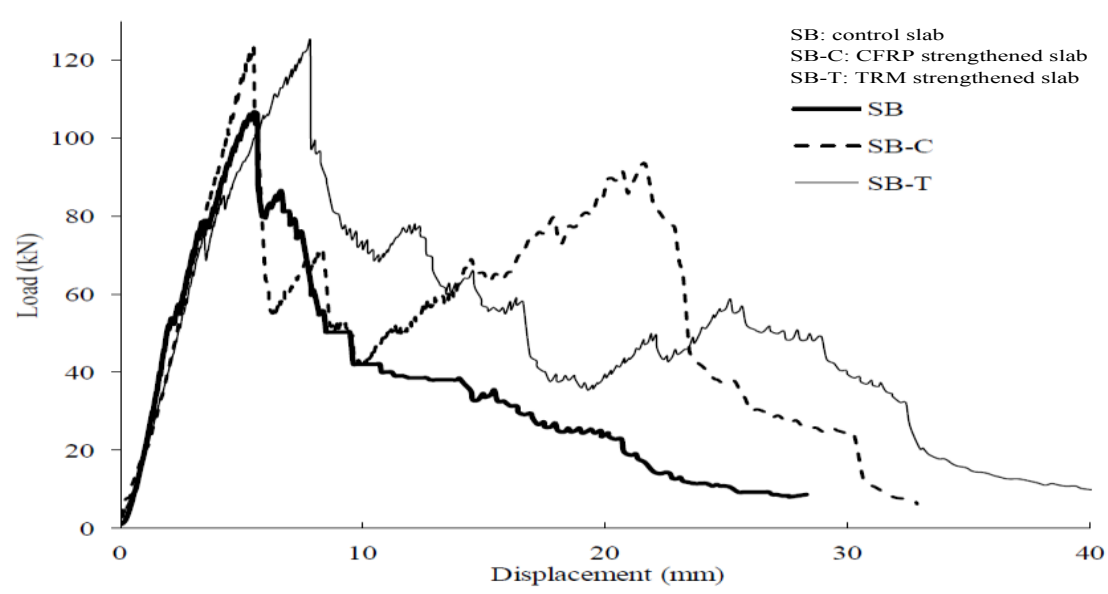

Figure 7: Load-Deflection curves of RC slabs [18]

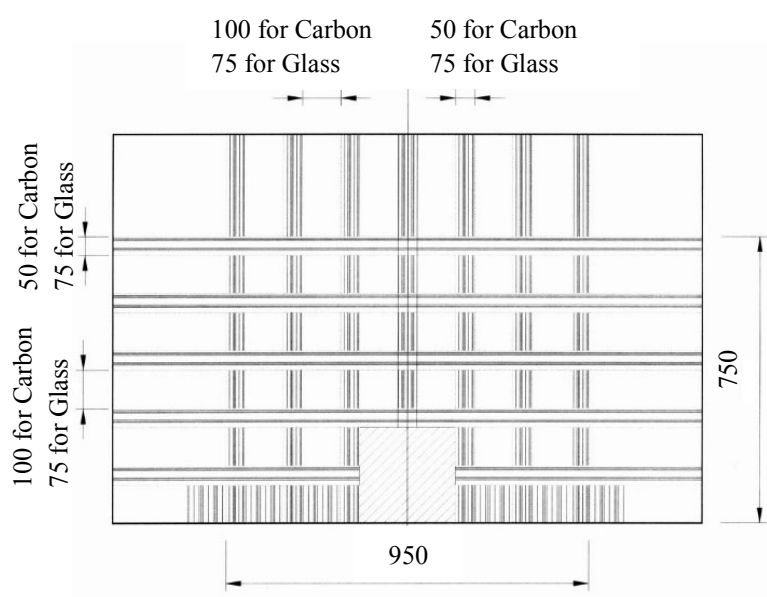

(a)

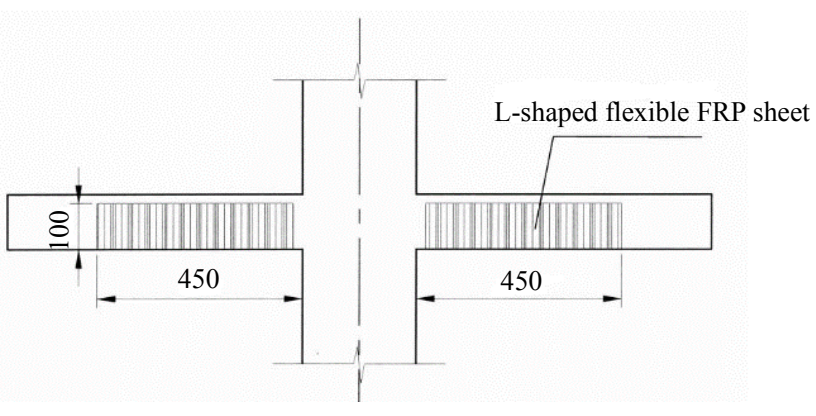

(b)

Figure 8: CFRP/GFRP strengthening layout application for flat slab specimens

(a) Straight strip, and (b) L-shape at the slab edges [19]

\section{Experimental Results of Literature}

This section reviews the experimental studies, which were used CFRP to strengthen the RC flat slabs in a brief way as illustrated in Table 2. It is noticed that many experiments have been done in general on models of limited size due to the available capacities in laboratories and construction costs. 
Table 2: Summary of experimental studies of load strength capacities of slabs subjected to punching shear

\begin{tabular}{ccccc}
\hline Reference & Slab No. & $\begin{array}{c}\text { CFRP sheets } \\
\text { (width/type) }\end{array}$ & $\begin{array}{c}\boldsymbol{f}_{\mathbf{c}} \\
(\mathbf{M P a})\end{array}$ & $\begin{array}{c}\boldsymbol{P}_{\mathbf{u}} \\
(\mathbf{k N})\end{array}$ \\
& & & & \\
& & & & \\
& & & & \\
& & & & \\
& & & & \\
& & & & \\
& & & & \\
& & & 31.9 & 49.2 \\
Harajli and & A1-SA1 & 50 & 29.1 & 47.4 \\
A1-SA1F5 & 100 & 34.3 & 65.4 \\
& A1-SA1F10 & 150 & 23.5 & 64.1 \\
& A2-SA2 & --- & 35.5 & 60.5 \\
A2-SA2F5 & 50 & 31.9 & 70.1 \\
& A2-SA2F10 & 100 & 35.5 & 77.7 \\
A2-SA2F15 & 150 & 23.5 & 80.0 \\
B1-SB1 & --- & 35.5 & 78.8 \\
& B1-SB1F10 & 50 & 31.9 & 114.5 \\
& B1-SB1F15 & 100 & 33.0 & 104.0 \\
& B1-B1F10(2L) & 150 & 34.3 & 107.5 \\
& B2-SB2 & --- & 29.1 & 122.0 \\
& B2-SB2F10 & 50 & 29.1 & 142.3 \\
B2-SB2F15 & 100 & 33.0 & 118.6 \\
& B2-B2F10(2L) & 150 & 34.3 & 123.3
\end{tabular}

Sharaf et al.

[15]

4-O-CFRP

4-S-CFRP

8-O-CFRP

8 -S-CFRP

8-O \& S-CFRP
Strips

Strips

Strips

Strips

Strips
421

420

451

456

462

477

1. The punching shear strength was increased by about ( $17 \%$ to $45 \%)$. This increase depends on the thickness of slab, steel reinforcement and CFRP ratio i.e. (area of sheets).

2. The debonding failure occurs at end supports for four specimens. As a result of the shear failure that was occurred between the adhesive film and the flat plate surface.

3. The cracks in the tensile area have restricted growth. Their appearance was delayed due to the increase in the flexural strength of slabs in corresponding to the use of CFRP. CFRP develops the shear resistance at slab column connection.

4. Failure in the bonding area was occurred suddenly when using CFRP stiffeners as two layers, which led to an increase in the horizontal shear force between the concrete surface and the fibre layer.

5. It was found that the CFRP gives an increase in the bending strength of the slab and develops the failure pattern from pure flexure to failure of combined flexure-shear or failure of pure shear.

1. CFRP was used to reduce and delay the appearance of cracks and control their distribution. Despite of stiffening all samples, the failure was punching shear.

2. Increasing the stiffening due to increased CFRP area or ratio improved the shear strength.

3. The reinforcement of the slabs with externally applied CFRP led to a reduction in the internal stress in the reinforcing steel bars. The results showed a good agreement with the ACI-318, BS8110, and CSA codes and standards in regarding to the resistance of punching shear.

1. CFRP strengthening was developed to reduce and delay the appearance of cracks and control their spread or distribution. The resulting failure despite stiffening of all samples was the failure of punching shear.

2. Increasing the stiffening due to increased CFRP area or ratio has improved the shear strength.

3. The reinforcement of the slabs with CFRP and their externally 


\begin{tabular}{|c|c|c|c|c|}
\hline \multirow{10}{*}{ Esfahani [17] } & $\mathrm{R} 0.8-\mathrm{C} 25-\mathrm{F} 0$ & \multirow{11}{*}{$\begin{array}{c}\text { CFRP sheets } \\
\text { externally } \\
\text { bonded }\end{array}$} & \multirow{11}{*}{23} & \\
\hline & $\mathrm{R} 0.8-\mathrm{C} 25-\mathrm{F} 10$ & & & 138 \\
\hline & $\mathrm{R} 0.8-\mathrm{C} 25-\mathrm{F} 10-\mathrm{CL}$ & & & 191 \\
\hline & $\mathrm{R} 0.8-\mathrm{C} 25-\mathrm{F} 15$ & & & 172 \\
\hline & $\mathrm{R} 0.8-\mathrm{C} 25-\mathrm{F} 15-\mathrm{CL}$ & & & 208.8 \\
\hline & R1.6-C25-F0 & & & 188 \\
\hline & R1.6-C25-F15 & & & 210 \\
\hline & R1 6-C25-F15-CL & & & 239 \\
\hline & $\mathrm{R} 16-\mathrm{C} 25-\mathrm{F} 30$ & & & 198 \\
\hline & R16-C25-F30-CL & & & 245 \\
\hline & & & & 210.5 \\
\hline
\end{tabular}

Abbas et al. [18]

SA-C
SA-T
SB (Non-CFRP)
SB-C
SB-T

\section{$\mathrm{XXX}$}

SF0

El-Salakawy et al. [19]

\section{SX-GF}

SX-CF

SX-GF-SB

SF-GF

SH-GF-SB

$\begin{array}{ccc} & 39.9 & 88.4 \\ \text { CFRP sheets } & 39.9 & 99.4 \\ \text { externally } & 39.9 & 96.4 \\ \text { bonded } & 63.2 & 106 \\ & 63.2 & 123.6 \\ & 63.2 & 125.2\end{array}$

33.0

125

GFRP strips

vertically

around the

column

31.5

32.0

110

130

$32.0 \quad 126$

$40.2 \quad 170$

$32.0 \quad 135$

$40.2 \quad 162$ applied to the concrete led to a reduction in the internal stress in the reinforcing steel bars. The results showed a good match with the ACI318, BS8110, and CSA codes specifications regarding resistance to punching shearing.

1. They observed a significant increase in the punching shear resistance when using carbon sheets for flexural strengthening of flat slabs.

2. It was found that the cyclical loading led to a reduction in strength of punching shear. The equations that were proposed from the Iranian code agree with the equations of the ACI code of punching shear resistance. Whereas, punching shear resistance formula suggested by British BS 8110 standard showed a greater accuracy and less scattering.

1. When analyzing the precipitation load response curves, it was found that there were two peaks for the unidirectional samples that were strengthened with carbon fibers in comparison to the non-reinforced ones.

2. They also believe that the second peak of the curve is the result of the combined effect of the iron wedge of the tension and bonding armament with unidirectional stiffeners.

3. The results showed that the carbon reinforced tiles give an increase in the total maximum load of the first peak by about 9 to $18 \%$, while the increase is greater in the load of the second peak.

1. When using CFRP sheets, the flexural stiffness and resistance to punching shear failure was increased with delaying opening of cracks. However, last failure was a result of punching shear.

2. It was found that the use of steel bolts along the CFRP, which was fixed to the concrete surface resulted in an increase in the ductility in the area of connection of the column with the slab. Also, it caused to convert the failure pattern from flexure to punching shear.

3. An increase in the resistance of punching shear was observed by ( $23 \%$ to $30 \%$ ) when installing the CFRP strips with the vertical steel bolts. The punching shear resistance calculated according to the ACI 318[9] and CSA [12] was conservative. 


\section{Conclusions}

This paper reviews the previous works that have been done during the last decades. The main findings in the reviewed papers in terms of the punching shear resistance of flat slabs can be drawn as follows:

1) The two most common techniques used to strengthen the region in closing to the column with CFRP strips/sheets include attaching of CFRP to the concrete surface around column at the tension side of the slab. Whereas the other is performed by fixing the CFRP strips/sheets vertically and by various methods to ensure the increase of the shear resistance.

2) There are many factors that influenced the development of load capacity including the orientation of CFRP strips in relation to the column support area, anchorage points, the area and quantity of the CFRP sheets/strips.

3) Strengthening by CFRP and fixing them perpendicularly to the flat slab at a specified distance from the face of the column provide an increase in the strength of punching shear when comparing with other methods of fixing CFRP plates on the tension side of the slab.

4) ACI-318 indicates that the flexural steel reinforcing is not combined with the capacity to withstand the punching shear forces. While other international codes and standards including the CSA and Eurocode 2 certify that flexural reinforcing steel contributes to the development of punching shear resistance.

\section{Recommendations for Future Works}

During reviewing the literature, there are many suggested points that can be taken into account to investigate other parameters, which can affect the punching shear resistance of RC slabs strengthened by using CFRP.

1) Realistic studies with the development of systems to monitor the behaviour of strengthened members with CFRP are needed.

2) Many studies are required to develop the design and qualification models for the building or the structural elements when using CFRP to strengthen them in various directions and in different positions. These design precautions are useful in determining all the structural characteristics, whether they are CFRP or reinforced concrete components.

3) Most of the previous studies have taken small or limited specimens, depending on the work in typical laboratories. Therefore, the need to study larger specimens is very required to have a real scenario to the behaviour of strengthened slabs with CFRP in punching shear failure.

4) Other methods for the purposes of fixing CFRP strips, sheets and laminates to the surface of a slab are needed to be developed to avoid the disturbance that results when strengthening the slab.

\section{Author Contribution}

All authors contributed equally to this work.

\section{Funding}

This research received no specific grant from any funding agency in the public, commercial, or not-for-profit sectors.

\section{Data Availability Statement}

The data that support the findings of this study are available on request from the corresponding author.

\section{Conflicts of Interest}

The authors declare that there is no conflict of interest.

\section{References}

[1] ACI Committee 440.1R-15, "Guide for the Design and Construction of Structural Concrete Reinforced with FiberReinforced Polymer Bars"; American Concrete Institute: Detroit, MI, USA, 2015.

[2] Oehlers, D.J. and Seracino R., "Design of FRP and Steel Plated RC Structures: Retrofitting Beams and Slabs for Strength, Stiffness and Ductility", Elsevier Ltd., 228pp, 2004.

[3] Alexander, S. and Simmonds S., "Shear-moment transfer in slab-column connections". In Structural Engineering Report; University of Alberta: Edmonton, AB, Canada, pp. 95, 1989.

[4] Guandalini, S., Burdet, O.L., Muttoni A., "Punching tests of slabs with low reinforcement ratios". ACI Struct. J., v. 106, $87-95,2009$.

[5] Silva, M.A.L., Madushanka, W.I., Ariyasena, P.S.I, Gamage, J.C.P.H, "Punching Shear Capacity Enhancement of Flat Slabs Using End Anchored Externally Bonded CFRP Strips"; Society of Structural Engineers: Colombo, Sri Lanka, 28, 2018. 
[6] Rasha, T.S.M, Amr, B., Hany, A., "Effect of flexural and shear reinforcement on the punching behavior of reinforced concrete flat slabs". Alex. Eng. J. vol. 56, 591-599, 2017.

[7] Al-Qraishi, H., "Detection of fibers content in UHPC slabs”. Eng. \& Tech. Journal, vol.33, part(A), No.3, 720-728, 2015.

[8] Sayhood, E.K., Hamood, M.J., Abdul Ridha, A.A., "Punching shear resistance of reinforced concrete flat plate slabs strengthened with CFRP”. Eng. \& Tech. Journal, vol.32, part(A), No.2, 511-529, 2014.

[9] Medhlom, M.K., "Punching shear behavior of fibrous self -compacting concrete flat slabs". Eng. \& Tech. Journal, vol.32, part(A), No.12, 2874-2890, 2014.

[10] ACI Committee 318M-318RM, "Building Code Requirements for Structural Concrete and Commentary": American Concrete Institute: Detroit, MI, USA, 2019.

[11] British Standards Institution BS8110, "Structural Use of Concrete-Code of Practice for Design and Construction", British Standards Institution, London, UK, 1997.

[12] European Committee for Standardization EN 1992-1-1, “Eurocode 2: Design of Concrete Structures-Part 1-1: General Rules and Rules for Buildings; The European Union per Regulation 305/2011”, European Committee for Standardization, Brussels, Belgium, 2004.

[13] Canadian Standards Association CAN/CSA S806-12, "Design and Construction of Building Structures with FiberReinforced Polymer", Canadian Standards Association, Toronto, ON, Canada, 2012.

[14] Harajli, M.H. and Soudki, K.A., "Shear strengthening of interior slab-column connections using carbon fiber-reinforced polymer sheets". J. Compos. Constr., vol. 7, 145-153, 2003.

[15] Sharaf, M.H., Soudki, K.A., Dusen, M.V., "CFRP strengthening for punching shear of interior slab-column connections". J. Compos. Constr., vol. 10, 410-418, 2006.

[16] Radik, M.J., Erdogmus, E., Schafer, T., "Strengthening two-way reinforced concrete floor slabs using polypropylene fiber reinforcement”. J. Mater. Civ. Eng. ASCE, vol. 23, 562-571, 2011.

[17] Esfahani, M.R., "Effect of cyclic loading on punching shear strength of slabs strengthened with carbon fiber polymer sheets". Int. J. Civ. Eng., vol. 6, 208-215, 2008.

[18] Abbas, H., Abadel, A.A., Almusallam, T., Al Salloum, Y., "Effect of CFRP and TRM strengthening of RC slabs on punching shear strength". Lat. Am. J. Solids Struct., vol. 12, 1616-1640, 2015.

[19] El-Salakawy, E., Soudki, K.A., Polak, M.A., "Punching shear behavior of flat slabs strengthened with fiber reinforced polymer laminates". J. Compos. Constr., vol. 8, 384-392, 2004. 